\title{
Culture of In Vitro Mouse Embryos with Fructose and Dipeptides Improves Development
}

\author{
Hirotada Tsujii* \\ Shinshu University, Japan \\ *Corresponding author: Hirotada Tsujii, Faculty of Agriculture, Minamiminowa-mura, Nagano 399-4598, Japan \\ Submission: 眥 August 8, 2017; Published: 眥 September 21, 2017
}

\begin{abstract}
Cultured mouse early embryos often fail to develop to the blastocyst stage, although 2-cell block can be released by culturing in CZB medium. We hypothesized that fructose in culture medium may improve the in vitro development of mouse embryos. To evaluate the embryotrophic role of fructose, mouse embryos were cultured in CZB medium contain fructose $(0.5,1.0,2.5$ or $5.0 \mathrm{mM})$. In this study, we compare whether glucose or fructose is metabolized most easily by mouse embryos at different stages of development. Seven-8- week-old cell block strain ICR mice were naturally mated after super ovulation. One-cell embryos were cultured in CZB medium supplemented with fructose.
\end{abstract}

When EDTA was added, 1-cell embryos developed to blastocysts but they did not develop in the presence of only fructose. The number of blastocysts and hatched blastocysts was significantly increased by the addition of fructose compared with that without fructose. The uptake and oxidation of 14C-fructose by pre-implantation embryos were significantly higher than those of 14C-glucose at all stage of embryo development. Furthermore, the quality of embryos produced by fructose and di-peptides, AlaGln or GlyGln supplementation instead of glutamine established this as an effective culture system for mouse embryos. The addition of AlaGln or GlyGln significantly increased the number of blastocysts and hatched blastocysts.

We improved the CZB medium with fructose, and determined that supplementation with AlaGln or GlyGln may be beneficial for culture medium for mouse early embryos.

Keywords: Embryo culture; Fructose; Glucose; Mouse embryo; Oxidation

Abbreviations: TCA: Tricarboxylic Acid Cycle; GlyGln: L-glycyl-L-Glutamine; PI: Propidium Iodide; PBS: Phosphate Buffered Saline; ICM: Inner Cell Mass; TE: Trophectoderm; PCA: Perchloric Acid; GFAT: Glutamine:Fructose-6-Phosphate Amidotransferase

\section{Introduction}

In mouse, development of 1-cell embryos to the blastocyst stage occurs readily for inbred strains, but out bred strains block in vitro at the 2-cell stage [1]. The development of mouse early embryo to the blastocyst stage is low, though 2-cell block can be released by culturing in the CZB medium [2]. The CZB medium contains lactate and pyruvate with glutamine, but without glucose. Glucose has been known to have a detrimental effect on early-stage development of embryos, but it supplies essential energy substrate to embryos at the compacted morula and blastocyst stages $[3,4]$.

The mechanisms responsible for the inhibition and retardation of development operate at the level of metabolism of the embryo. In early development, mouse embryos rely on the tricarboxylic acid cycle (TCA) for energy production, primarily using pyruvate as a metabolic substrate. The switch to glycolysis occurs after the embryonic genome has been activated, at or close to compaction [5-9]. The inability of the embryo to use glucose is due to the low concentrations of phosphofructokinase that are present in early embryos. Embryos are able to take up glucose, which is then phosphorylated by hexokinase, using energy, but it cannot be metabolized further owing to the lack of phosphofructokinase [10].

Like glucose, fructose is a monosaccharide hexose capable of entering the glycolytic pathway, and may be more suitable in providing the embryo with its energy needs, while not inhibiting early development. Replacement of glucose with fructose in a culture medium supported the development of embryos at the cleavage stage as well as glucose-containing medium, and fructose can increase total cell numbers in both hamster and bovine blastocysts $[11,12]$. Fructose is present in the reproductive tract of many species [13-17] and effectively supported embryonic development in mouse [18], hamster [12] and bovine [11] embryos.

Amino acids have been shown to be key regulators of embryo development and viability, but they spontaneously break down in culture to produce ammonium [19,20]. Chatot et al. [2] found that glucose-free medium containing glutamine and EDTA alleviates the 2-cell block exhibited by embryos from outbred strains of mice in vitro. Dipeptides such as L-alanyl-L-glutamine (AlaGln) and 
L-glycyl-L-glutamine (GlyGln) are stable in solution and are suitable as a source of glutamine [21]. Glutamine-containing dipeptides such as AlaGln and GlyGln have also been considered as a replacement for glutamine in culture systems [22]. Biggers et al. [23] reported that the addition of the dipeptides AlaGln and GlyGln can plays an important role in in vitro pre implantation in mouse embryos.

In this study, we examined the role of fructose in the early developmental embryos, and incorporation of fructose in vitro. Furthermore, the qualities of embryos produced by fructose and dipeptides supplementation were evaluated to establish an effective culture system for mouse embryos.

\section{Materials and Methods}

\section{Animals}

Embryos were obtained from Seven-8- week-old female ICR mice. They were offered feed with a standard diet and tap water ad libitum. Animals were kept in polycarbonate cage with wood shavings under a $12 \mathrm{~h}$ light: $12 \mathrm{~h}$ dark regimen (light on at 6:00),

Table 1: Components of culture medium.

\begin{tabular}{|c|c|c|c|}
\hline & $\mathrm{mg} / 100 \mathrm{ml}(\mathrm{mM}) \mathrm{CZB}$ & f-CZB & f-CZB-A \& f-CZB-G \\
\hline $\mathrm{NaCl}$ & $479.2(82.00)$ & $464.6(79.5)$ & $464.6(79.5)$ \\
\hline $\mathrm{KCl}$ & $36.2(4.86)$ & $36.2(4.86)$ & $36.2(4.86)$ \\
\hline $\mathrm{KH}_{2} \mathrm{PO}_{4}$ & $15.9(1.17)$ & $15.9(1.17)$ & $15.9(1.17)$ \\
\hline $\mathrm{CaCl} 2$ & $19(1.71)$ & $19(1.71)$ & $19(1.71)$ \\
\hline $\mathrm{MgSO}_{4}-7 \mathrm{H}_{2} \mathrm{O}$ & 29.1(1.18) & 29.1(1.18) & 29.1(1.18) \\
\hline $\mathrm{NaHCO}_{3}$ & $210.0(25.00)$ & $210.0(25.00)$ & $210.0(25.00)$ \\
\hline Na-pyruvate & $2.9(0.26)$ & $2.9(0.26)$ & $2.9(0.26)$ \\
\hline Na-lactate & $0.43 \mathrm{ml}(30.10)$ & $0.43 \mathrm{ml}(30.10)$ & $0.43 \mathrm{ml}(30.10)$ \\
\hline Glutamine & $14.6(1.00)$ & $14.6(1.00)$ & $14.6(1.00)$ \\
\hline EDTA & $3.7(0.10)$ & $3.7(0.10)$ & $3.7(0.10)$ \\
\hline Penicillin & $6.5(10000 \mathrm{IU})$ & $6.5(10000 \mathrm{IU})$ & $6.5(10000 \mathrm{IU})$ \\
\hline Streptomycin & 7 & 7 & 7 \\
\hline BSA & 500 & 500 & 500 \\
\hline Fructose & - & $90.0(5.0)$ & $90.0(5.0)$ \\
\hline AlaGln & - & - & -1 \\
\hline GlyGln & - & - & -2 \\
\hline
\end{tabular}

\section{Collection of embryos}

Embryos of 1-, 2-, 4-, 8-cell stages and blastocyst were collected $25,40,62,68$ and 86 hours after the hCG injection, respectively. These embryos were flushed out from the fallopian tubes or uterine horn. The embryos were subsequently incubated in CZB with fructose (f-CZB). Embryos were cultured according to standard techniques, in groups of 10 embryos in $30 \mu$ d droplets under mineral oil (Sigma, USA) at $37^{\circ} \mathrm{C}$ and $5 \% \mathrm{CO}_{2}$ in air. In each experiment, the embryos were examined at 24 hours intervals to assess the embryo development.

\section{Culture of embryos}

Flushed 1-cell stage embryos were collected with a micropipette and transferred to the culture dishes. Clean 1-cell stage embryos at a temperature of $20 \pm 1^{\circ} \mathrm{C}$ in accordance with the "Guideline for Regulation of Animal Experimentation, Faculty of Agriculture, Shinshu University." Female mice were induced to superovulated with PMSG (5 IU, i.p.) followed $48 \mathrm{hr}$ later by hCG (5 IU, i.p.). Both Chemical Industries Ltd., Tokyo, Japan. The copulation plug was checked 24 hours later.

\section{Embryo culture medium}

The basic medium used in this study was CZB [2], which contains $1 \mathrm{mM}$ glutamine $0.1 \mathrm{mM}$ EDTA, and $5 \mathrm{mg} / \mathrm{ml} \mathrm{BSA}$ and lacks glucose, with fructose. The formulation is as follows: 82.0; 79.5: addition of fructose, $\mathrm{mM} \mathrm{NaCl}, 4.86 \mathrm{mM} \mathrm{KCl}, 1.17 \mathrm{mM} \mathrm{KH}_{2} \mathrm{PO}_{4}, 1.71 \mathrm{mM}$ $\mathrm{CaCl}_{2}, 1.18 \mathrm{mM} \mathrm{MgSO}_{4} \cdot \mathrm{H}_{2} \mathrm{O}, 25.0 \mathrm{mM} \mathrm{NaHCO}_{3}, 0.26 \mathrm{mM}$ Na-pyruvate, $30.1 \mathrm{mM} \mathrm{Na}$ - lactate, $1.0 \mathrm{mM}$ glutamine, and $5 \mathrm{mg} / \mathrm{ml}$ BSA (Table 1). The osmolarity of CZB was adjusted to $280 \mathrm{mOsm}$ by increased $\mathrm{NaCl}$ concentration when determined by freezing point depression using the Advanced micro osmo meter (Advanced instruments inc, Norwood, MA, USA). PMSG and hCG used in this study were obtained from Sankyo were grown in-vitro to the developmental stages to blastocyst. Groups of 8-10 zygotes were placed into 35-mm-diameter culture dishes (Nunc Co., Denmark) containing $30 \mu$ l of each f-CZB medium under a layer of paraffin oil (Nacalai Tesque Inc., Kyoto, Japan) and equilibrated in an atmosphere of $5 \% \mathrm{CO} 2$ in air at $37^{\circ} \mathrm{C}$ overnight. The $\mathrm{pH}$ of all media was 7.4 after equilibration. The developing embryos seemed to be normal in their morphology, with almost no fragmentation. All salts, carbohydrates and amino acids were purchased from Nacalai Tesque Inc. (Kyoto, Japan). BSA was purchased from Sigma-Aldrich.

\section{Blastocyst cell count}

After culturing, embryos were stained with hoechst 33342 and propidium iodide (PI). Embryos were stained for $30 \mathrm{sec}$ in PI 
solution PI $0.1 \mathrm{mg} / \mathrm{ml} 0.2 \%$ Triton X-100 in phosphate buffered saline (PBS) which included neither calcium nor magnesium, and kept overnight in Hoechst 33342 solution $(25 \mu \mathrm{g} / \mathrm{ml}$ hoechst 33342 , $99.5 \%$ ethanol). They were then washed with glycerol, observed under fluorescence microscope (IX-70 Olympus Co., Japan), and cell numbers were counted. The inner cell mass (ICM) showed blue fluorescence and trophectoderm (TE) showed pink fluorescence under $352 \mathrm{~nm}$ light. The number of TE and ICM cells in all the blastocysts was ascertained at $139 \mathrm{~h}$ post-hCG.

\section{Incorporation and oxidation of radio labeled fructose and glucose}

The experiment was initiated with $14 \mathrm{C}$-glucose $18.5 \mathrm{kBq} / 0.1 \mathrm{~mol}$ (specific activity $9.69 \mathrm{MkBq} / \mathrm{mol}$ ) or $14 \mathrm{C}$-fructose $18.5 \mathrm{kBq} / 0.1 \mathrm{~mol}$ (specific activity $11.1 \mathrm{MBq} / \mathrm{mol}$ ) (Moravek Biochemicals, Inc., CA. USA). Each of the five embryos at a particular stage of development was transferred in a micro tube of $50 \mu \mathrm{L}$ CZB medium drop containing 14C-fructose or 14C-glucose then overlaid with mineral oil. On the other hand, $1 \mathrm{ml}$ of $2.5 \mathrm{mM} \mathrm{NaOH}$ solution was transferred into a $1.5 \mathrm{~mL}$ micro tube as a trap for the evolved $14 \mathrm{CO}_{2}$. Both micro tubes of $\mathrm{NaOH}$ and 14C-fructose or 14C-glucose with embryos were confined into a scintillation vial using a rubber stopper. The scintillation vials were incubated for $5 \mathrm{~h}$ in incubator at $37^{\circ} \mathrm{C}$. After incubation period, the metabolic reactions of embryos were stopped with an injection of $100 \mu \mathrm{L}$ of $10 \%$ perchloric acid (PCA) kept at room temperature for $24 \mathrm{~h}$. The acid insoluble materials were carefully washed by millipore filtration $(8.0 \mu \mathrm{M}$ white SCWP, $47 \mathrm{~mm}$; Millipore Corporation, Bedford, MA, USA) with 5\% PCA and the filter papers were kept overnight under a lamp. After drying, the filter papers were transferred into scintillation vials. The $\mathrm{NaOH}$ solution was transferred into a new scintillation vial by washing 3-4 times with cocktail $(0.5 \%$ PPO $+0.03 \%$ POPOP solution in toluene). All the scintillation vials with $5 \mathrm{ml}$ of cocktail were set in a liquid scintillation counter (LS-6500, Beckman Instruments, Inc. USA) to determine the levels of radioactivity. This experiment was conducted three times to improve its accuracy. The values of incorporation and oxidation were expressed directly as counts per minutes (cpm).

\section{Dipeptides}

Gln, AlaGln, GlyGln and all other chemicals were purchased from Nacalai Tesque (Kyoto, Japan). The effect of Gln and dipeptides were examined development of 1-cell embryo at $1.0 \mathrm{mM}$ and $2.0 \mathrm{mM}$. The accumulation of ammonia in culture medium was evaluated by adding Gln and dipeptides.

\section{Ammonia determination}

During incubation periods, the ammonia concentrations in the medium were assessed using the Bertholot-indophenol method as described in our previous study [24-28]. To determine the ammonia concentration in the medium, $100 \mu \mathrm{L}$ of the culture medium was removed every $2-4 \mathrm{~h}$ and frozen at $-40^{\circ} \mathrm{C}$ until measurement. The procedure was carried out five times for the analysis. A calibration curve in the range $0-0.30 \mathrm{mMl}$ ammonia was run with each experiment. The mean coefficient for determination of the calibration curve of five experiments was 0.994 .

\section{Experimental design}

a. In the first experiment, development from 1-, 2-, and 8-cell stage to the blastocyst was examined in combining fructose, pyruvate, lactate, and EDTA. $5 \mathrm{mM}$ fructose, $0.26 \mathrm{mM}$ Na-pyruvate, $30.1 \mathrm{mM}$ Na-lactate, and $0.1 \mathrm{mM}$ EDTA were added to the CZB medium where Na-pyruvate, Na-lactate, and EDTA were withdrawn from the medium.

b. In the second experiment, the optimal concentrations of fructose were compared with $0.5,1.0$, and 2.5 and $5.0 \mathrm{mM}$, used CZB medium.

c. In the third experiment, incorporation and oxidation of radio labeled fructose and glucose at

d. In the fourth experiment, development from 1-cell stage to the blastocyst was examined in combining f-CZB and dipeptides instead of glutamine. The amount of the ammonia accumulation of medium and the cell number of blasocysts were measured.

\section{Statistical analysis}

The results are presented as mean $\pm \mathrm{SD}$, and statistical analysis was performed using $\chi 2$ test and analysis of variance. A value of $\mathrm{P}<0.05$ was considered to be statistically significant.

\section{Results}

\section{Experiment 1}

The effect of fructose on the development of pre-implantation mouse embryo is shown in Table 2. It has developed to the blastocyst only by 8-cell stage in the culture medium with fructose, lactate and pyruvate. It has developed to the blastocyst stage because of 1- cell stage when EDTA is added to this medium.

Table 2: Effects of energy substrate and EDTA on the development of blastocysts from 1-, 2-, and 8-cell mouse embryos.

\begin{tabular}{|c|c|c|c|}
\hline \multirow{2}{*}{$\begin{array}{c}\text { Energy } \\
\text { Substrate }\end{array}$} & \multicolumn{3}{|c|}{ Number of Embryos (\%) } \\
\cline { 2 - 4 } & cell@blastocyst & cell@blastocyst & $\begin{array}{c}\text { 8 } \\
\text { cell@blastocyst }\end{array}$ \\
\hline F & $0 / 30(0)$ & $0 / 36(0)$ & $32 / 32(100)$ \\
\hline F+P+L & $0 / 33(0)$ & $0 / 43(0)$ & $36 / 36(100)$ \\
\hline F+P+L+E & $17 / 56(30.4)$ & $21 / 51(41.2)$ & $33 / 33(100)$ \\
\hline
\end{tabular}

F:Fructose, P:Pyruvate, L:Lactate, E:EDTA.

Values in parentheses indicate percentage. Data expressed are for four replicates. 


\section{Experiment 2}

Effect of different concentration of fructose on the development of mouse 1-cell stage embryos is shown in the Table 3. Addition of $0.5,1.0,2.5$ or $5.0 \mathrm{mM}$ fructose significantly increased number of blastocyst and hatched blastocyst as compared to without fructose. There is no significant difference in blastocyst by fructose 0.5 and $1.0 \mathrm{mM}$ addition. The highest rate of embryo development was found with $0.5 \mathrm{mM}$ fructose, development rate was decreased as the concentration of fructose increased. Moreover, fructose $1.0 \mathrm{mM}$ increased hatched blastocyst was higher than that of other concentrations.

Table 3: Effects of different concentrations of fructose on the development of mouse blastocysts and hatched blastocysts.

\begin{tabular}{|c|c|c|c|c|}
\hline \multirow{2}{*}{$\begin{array}{c}\text { Fructose } \\
\begin{array}{c}\text { Concentration } \\
(\mathbf{m M})\end{array}\end{array}$} & $\mathbf{n}$ & \multicolumn{3}{|c|}{ Number of Embryos (\%) } \\
\cline { 3 - 5 } & & Morula & Blastocyst & $\begin{array}{c}\text { Hatched } \\
\text { Blastocyst }\end{array}$ \\
\hline 0 & 48 & $38(79.2)$ & $3(6.3)^{\mathrm{a}}$ & $0(0)^{\mathrm{e}}$ \\
\hline 0.5 & 47 & $40(85.1)$ & $35(74.5)^{\mathrm{c}}$ & $14(29.8)^{\mathrm{fg}}$ \\
\hline 1 & 48 & $39(81.2)$ & $34(70.8)^{\mathrm{c}}$ & $21(43.8)^{\mathrm{g}}$ \\
\hline 2.5 & 50 & $38(76.0)$ & $24(48.0)^{\mathrm{bc}}$ & $13(26.0)^{\mathrm{fg}}$ \\
\hline 5 & 48 & $35(72.9)$ & $19(39.6)^{\mathrm{b}}$ & $9(18.8)^{\mathrm{f}}$ \\
\hline
\end{tabular}

Values in parentheses indicate percentage. Data expressed are for four replicates.

Different superscripts within the same column indicate significant differences $(\mathrm{p}<0.05)$.

\section{Experiment 3}

The incorporation and oxidation of 14C-glucose and 14C-fructose on pre-implantation embryos is shown in Figure $1 \& 2$. The incorporation of $14 \mathrm{C}$-glucose was significantly lower than those of 14C-fructose on pre-implantation embryos, at the 2 -cell, 4-cell embryos and blastocysts $(\mathrm{p}<0.05)$. The oxidation of 14C-glucose was significantly lower than those of $14 \mathrm{C}$-fructose at all stage of embryos $(\mathrm{p}<0.05)$.

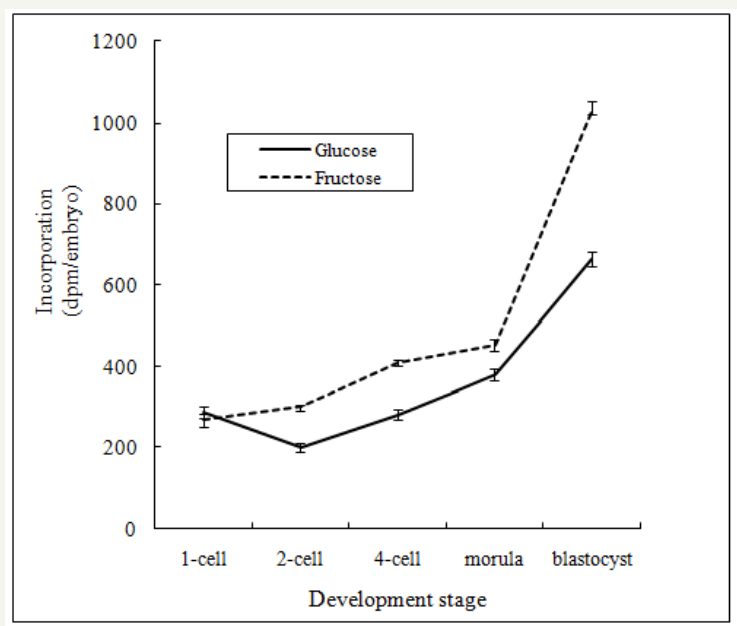

Figure 1: Incorporation of radioactive glucose and fructose by mouse pre-implantation embryos. Data expressed are for four replicates.

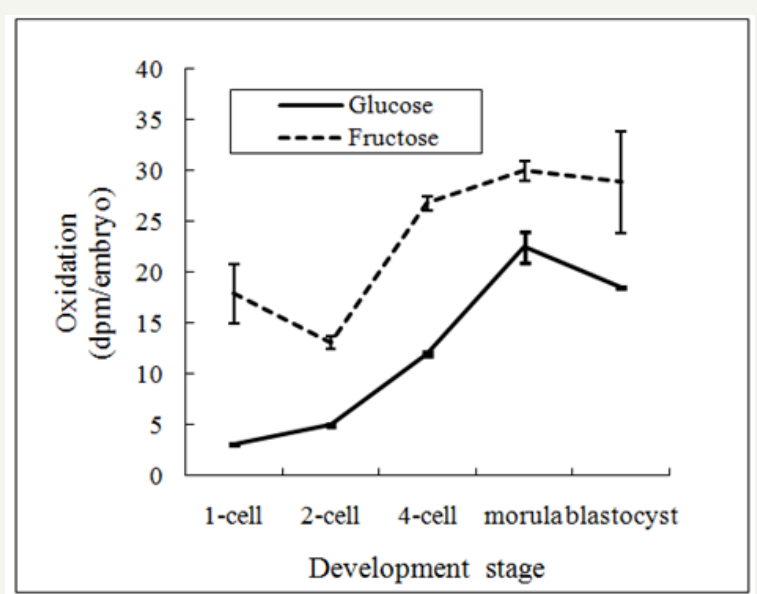

Figure 2: Oxidation of radioactive glucose and fructose by mouse pre-implantation embryos. Data expressed are for four replicates.

\section{Experiment 4}

The effect of dipeptides instead ofglutamine on the development of blastocyst mean cell numbers is shown in Table 4. Glutamine was added to the culture medium of $\mathrm{f}-\mathrm{CZB}$, there was no difference in development rate of blastocysts and hatched blastocysts. Addition of $1.0 \mathrm{mM}$ and $2.0 \mathrm{mM}$ of AlaGln and GlyGln significantly increased number of blastocysts and hatched blastocysts, number of ICM and TE as compared with control and Gln.

Table 4: Effects of dipeptides instead of glutamine f-CZB on the development of mouse blastocysts.

\begin{tabular}{|c|c|c|c|c|}
\hline \multirow{2}{*}{$\begin{array}{c}\text { Fructose } \\
(\mathbf{m M})\end{array}$} & $\begin{array}{c}\text { Amino } \\
\text { Acid/ } \\
\text { Dipeptides }\end{array}$ & $\mathbf{n}$ & Blastocyst & $\begin{array}{c}\text { Hatched } \\
\text { Blastocyst }\end{array}$ \\
\cline { 4 - 5 } & (control) & 90 & $48(53.33)^{\mathrm{b}}$ & $8(8.9)^{\mathrm{ef}}$ \\
\hline \multirow{2}{*}{0} & Gln & 90 & $52(57.8)^{\mathrm{bc}}$ & $8(8.9)^{\mathrm{ef}}$ \\
\cline { 2 - 5 } 1 & Ala-Gln & 90 & $71(77.9)^{\mathrm{d}}$ & $14(15.6)^{\mathrm{ef}}$ \\
\cline { 2 - 5 } & Gly-Gln & 90 & $74(82.2)^{\mathrm{d}}$ & $10(11.1)^{\mathrm{ef}}$ \\
\hline \multirow{2}{*}{2} & Gln & 90 & $28(31.1)^{\mathrm{a}}$ & $28(2.2)^{\mathrm{f}}$ \\
\cline { 2 - 5 } & Ala-Gln & 90 & $73(81.1)^{\mathrm{d}}$ & $7(7.8)^{\mathrm{e}}$ \\
\cline { 2 - 5 } & Gly-Gln & 90 & $69(76.7)^{\mathrm{cd}}$ & $16(17.8)^{\mathrm{ef}}$ \\
\hline
\end{tabular}

Values in parentheses indicate percentage. Data expressed are for four replicates.

Different superscripts within the same column indicate significant difference $(\mathrm{p}<0.05)$.

The effect of amino acids/ dipeptides on the development of ammonia concentrations in the medium is shown in Figure 3. The accumulated ammonia $1.0 \mathrm{mM}$ and $2.0 \mathrm{mM}$ of AlaGln and GlyGln was significantly lower than control and Gln. In the presence of fructose, supplementation of Ala-Gln and Gly-Gln significantly reduced ammonium concentration in the medium $(\mathrm{P}<0.05)$. 


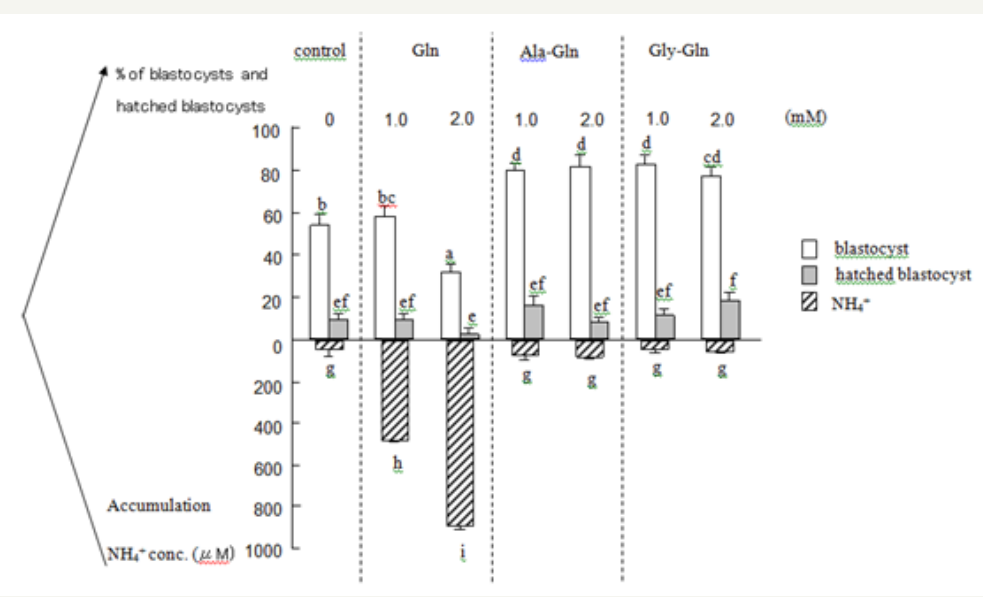

Figure 3: Accumulation of ammonia in culture medium and embryo development. Data are expressed as mean \pm S.E; different superscripts indicate significant difference $(\mathrm{p}<0.05)$.

Effect of amino acids/dipeptides on the cell number of blastocyst is shown in Table 5. Compared to the control, supplementation of dipeptides (Gly-Gln) significantly increased ICM, TE and total cell number.

Table 5: Effects of amino acids/dipeptides on blastocyst cell number.

\begin{tabular}{|c|c|c|c|c|c|}
\hline \multirow{2}{*}{ Concentration(mM) } & \multirow{2}{*}{ Amino Acids/Dipeptides } & \multirow{2}{*}{$\mathbf{n}$} & \multicolumn{3}{|c|}{ Cell Number } \\
\hline & & & ICM & $\mathrm{TE}$ & Total \\
\hline 0 & (control) & 7 & $9.1 \pm 1.3^{\mathrm{ab}}$ & $40.1 \pm 5.5^{c}$ & $49.3 \pm 4.7^{\mathrm{ef}}$ \\
\hline \multirow{3}{*}{1} & Gln & 7 & $8.0 \pm 1.1^{\mathrm{a}}$ & $47.0 \pm 2.7^{\mathrm{cd}}$ & $55.0 \pm 3.1^{\mathrm{efg}}$ \\
\hline & Ala-Gln & 7 & $13.3 \pm 1.9^{\mathrm{ab}}$ & $53.6 \pm 4.2^{\text {cd }}$ & $66.9 \pm 3.9^{g h}$ \\
\hline & Gly-Gln & 7 & $15.1 \pm 2.0^{\mathrm{b}}$ & $62.3 \pm 4.8^{\mathrm{d}}$ & $77.4 \pm 4.1^{\mathrm{h}}$ \\
\hline \multirow{3}{*}{2} & Gln & 7 & $7.3 \pm 1.1^{\mathrm{a}}$ & $39.6 \pm 2.9^{c}$ & $46.9 \pm 3.8^{\mathrm{e}}$ \\
\hline & Ala-Gln & 7 & $10.4 \pm 1.8^{\mathrm{ab}}$ & $54.9 \pm 3.0^{\text {cd }}$ & $65.3 \pm 3.4^{\text {fgh }}$ \\
\hline & Gly-Gln & 7 & $13.3 \pm 1.7^{\mathrm{ab}}$ & $55.9 \pm 4.3^{\mathrm{cd}}$ & $69.1 \pm 4.2^{\mathrm{gh}}$ \\
\hline
\end{tabular}

Values in parentheses indicate percentage. Data expressed are for four replicates. Different superscripts within the same column indicate significant differences $(\mathrm{p}<0.05)$.

\section{Results and Discussion}

In the present study, one-cell mouse embryos were cultured to the blastocyst stage in CZB medium with fructose, where number of blastocysts and hatched blastocysts were increased. Like glucose, fructose and galactose are monosaccharides hexoses capable of entering the glycolytic pathway. Fructose is present in the reproductive tract of many species [13,15-17,24,25] and can be metabolized by pre implantation embryos [19]. Replacement of glucose with fructose in a culture medium supported the development of embryos at the cleavage stage as well as glucosecontaining medium, and fructose can increase total cell numbers in mouse, hamster and bovine blastocysts $[11,12,18]$.

Ménézo \& Khatchadourian [26] reported that replacement of glucose in Whittingham M16 culture medium by fructose, do not block at the 2-cell stage and high rates of blastocyst formation (53.6\%) Swiss one cell embryos. In present study, mouse 2-cell embryo didn't developed on fructose only, fructose with pruvate and lactate. And, the addition of EDTA increased the numbers of blastocysts. Abramczuk et al. [27] overcame this block by adding EDTA to Whitten's medium [28]. Although the 2-cell block was not absolute in the strains of mice they used, the addition of EDTA spanning a range of concentrations increased the numbers of blastocysts.

In this experiment, the osmolality was adjusted to $280 \mathrm{~m} 0 \mathrm{sm}$. The osmolality was always 290-300m0sm of mouse embryo culture medium [29]. Dawson and Baltz reported that embryo development was severely inhibited by increased osmolarity, with nearly $100 \%$ development to the 4-cell stage at $250 \mathrm{mOsm}$ but no development to this stage at $300 \mathrm{mOsm}$ or above [30]. Sakkas et al. [31] reported that the best concentration of fructose was $0.5 \mathrm{mM}$ used in M16 in mouse embryos. In this experiment, a significant difference was not observed between 0.5 and $1.0 \mathrm{mM}$ fructose supplementation for blastocysts development. Moreover, fructose $1.0 \mathrm{mM}$ enhanced number of hatched blastocysts.

In this experiment, the incorporation and oxidation of 14C-fructose were significantly higher than those of 14C-glucose in pre-implantation embryos. Any glucose that enters the embryo is rapidly and irreversibly phosphorylated by hexokinase to form glucose-6-phosphate [32]. The subsequent utilization of glucose-6phosphate in glycolysis is blocked in early embryonic development 
and this blockis thoughtto occur at the enzyme phosphofructokinase, which converts fructose-6-phosphate to fructose-1,6-phosphate [33]. Ménézo \& Khatchadourian [26] reported that glucose may stimulate premature glycogen synthesis in the embryo, whereas fructose, which enters glycolysis downstream of glucose, may not be directed towards glycogen synthesis.

Glucose and fructose may also benefit embryos by increasing the efficacy of protein synthesis. Both glucose and fructose are substrates for glutamine:fructose-6-phosphate amidotransferase (GFAT), the first and rate-limiting enzyme in the hexosamine pathway necessary for post-translational protein glycosylation [34]. Furthermore, there is evidence that increasing the availability of fructose-6-phosphate serves to regulate the activity of GFAT [35]. Energy-demanding biological processes, including protein synthesis, nucleic acid synthesis, and ion transport, increase the need for and cause an elevation in metabolic activity leading up to the blastocyst stage [36,37].

Glutamine is readily taken up and metabolized by the mouse embryo at each stage during the pre implantation period $[11,12,19]$. In this experiment, glutamine did not significantly increase development rate to blastocysts and hatched blastocysts, added to the culture medium of fructose. We speculate that it probably sufficient with fructose, a source of energy of the embryos did not increase development rates of the embryos. Although, amino acids plays an important role for the embryo culture.

The accumulation of embryo-toxic ammonium in culture medium might be explained by the results of previous studies [38] that failed to show a beneficial effect of amino acids on embryonic development in vitro. The toxic effect of glutamine can be avoided by using dipeptides that can be directly used by the mammalian cells in vitro. Dipeptides such as L-alanyl-L-glutamine (AlaGln) and L-glycyl-L-glutamine (GlyGln) are stable in solution and are suitable as a source of glutamine [39].

Glutamine containing dipeptides such as AlaGln and GlyGln have also been considered as a replacement for glutamine in culture system [40], and the addition of these dipeptides enhanced higher rates of embryo development in the mouse. Biggers et al. [41] reported that the addition of the dipeptides AlaGln and GlyGln can play an important role in pre-implantation mouse embryos. In this experiment, addition of AlaGln and GlyGln was significantly increased number of blastocysts and hatched blastocyst, number of ICM and TE as compared with control and Gln. And the accumulation of ammonia in AlaGln and GlyGln treated medium significantly lower than the control and Gln.

These results presented in this paper collectively suggest that CZB medium supplemented with fructose, EDTA and 1.0mM AlaGln (fCZB-A) or 2.0mM GlyGln (fCZB-G ) might be good culture medium for mouse early embryos.

\section{References}

1. Goddard MJ, Pratt HPM (1983) Control of events during cleavage of the mouse embryo:an analysis of the "2cell block." J Embryol Exp Morphol 73: 111-133.
2. Chatot CL, Ziomek CA, Bavister BD, Lewis JL, Torres I (1989) An improved culture medium supports development of random-bred-cell mouse embryos in vitro. J Reprod Fertil 86(2): 679-688.

3. Flood MR, Wiebold JL (1988) Glucose metabolism by preimplantation pig embryos. J Reprod Fertil 84(1): 7-12.

4. Kikuchi K, Onishi A, Kashiwazaki N, Iwamoto M, Noguchi J, et al. (2002) Successful piglet production after transfer of blastocysts produced by a modified in vitro system. Biol Reprod 66(4): 1033-1041.

5. Brinster RL (1965) Studies on the development of mouse embryos in vitro. IV. Interaction of energy sources. J Rep Fert 10(2): 227-240.

6. Brinster RL (1965b) Studies on the development of mouse embryos in vitro. II. The effect of energy source. J Exp Zoology 158 (1): 59-68.

7. Biggers JD, Whittingham DG, Donahue RP (1967) The pattern of energy metabolism in the mouse oocyte and zygote. Proc Natl Acad Sci U S A 58(20): 560-567.

8. Leese HJ (2012) Metabolism of the pre implantation mammalian embryo. Reproduction 143(4): 417-427.

9. Gardner DK, Sakkas D (1993) Mouse embryo cleavage, metabolism and viability: role of medium composition. Hum Reprod 8(2): 288-295.

10. Houghton FD, Sheth B, Moran B, Leese HJ, Fleming TP (1996) Expression and activity of hexokinase in the early mouse embryo. Mol Hum Reprod 2(10): 793-798

11. Kwun J, Chang K, Lim J, Lee E, Lee B, et al. (2003) Effects of exogenous hexoses on bovine in vitro fertilized and cloned embryo development: improved blastocyst formation after glucose replacement with fructose in a serum-free culture medium. Mol Reprod Dev 65(2): 167-174.

12.Ludwig TE. Lane M, Bavister BD (2001) Differential effect of hexoses on hamster embryo development in culture. Biol Reprod 64(5): 1366-1374.

13. Aitken RJ (1976) Uterine secretion of fructose in the red deer. J Reprod Fertil 46: 39-440.

14.Gregorie AT, Gibbon R (1965) Glucosyl oligosacchrides of the rabbit genital tract: effects of ovarian hormone administration. Int J Fertil 10: 151-157.

15. Greven H, Baldus BB (1984) The distribution of monosaccharides and hexosamines in the oviduct of Salamandra salamandra (L.) (Amphibia, Urodela), Comp Biochem Physiol B 79(2): 229-232.

16. Haynes NB, Lamming GE (1967) The carbohydrate content of sow uterine flushings. J Reprod Fertil 14(2): 335-337.

17.Suga T, Masaki J (1973) Studies on the secretions of the cow. 6. Sugar and polyol constituents in the luminal fluid of the bovine uterus. Jpn J Anim Reprod 18: 143-147.

18.Sakkas D, Urner F, Menezo Y, Leppens G (1993) Effects of glucose and fructose on fertilization, cleavage, and viability of mouse embryos in vitro, Biol Reprod 49(6): 1288-1292.

19. Gardner DK, Lane M (1993) Amino acids and ammonium regulate mouse embryo development in culture. Biol Reprod 48(2): 377-385.

20. Heeneman S, Deutz NE, Buurman WA (1993) The concentrations of glutamine and ammonia in commercially available cell culture media. J Immunol Methods 166(1): 85-91.

21.Adibi SA, Lochs H, Abumrad NN, Daniel H, Vazquez JA (1993) Removal of glycyl glutamine by individual tissues: mechanism and impact on amino acid fluxes in postabsorption and starvation. J Nutr 123(2suppl): 325331.

22. Roth E, Ollenschlager G, Hamilton Simmel GA, Langer K, Fekl W, Jakesz $R$ (1988) Influence of two lutamine-containing dipeptides on growth of mammalian cells. In Vitro. Cell Dev Biol Anim 24(7): 696-698.

23. Biggers JD, McGinnis LK, Lawitts JA (2004) Enhanced effect of glycyl-Lglutamine on mouse preimplantation embryos in vitro. Reprod Biomed Online 9(1): 59-69. 
24. Gregorie AT, Gibbon R (1965b) Glucosyl oligosacchrides of the rabbit genital tract: effects of ovarian hormone administration. Int J Fertil 10: 151-157.

25. Douglas CP, Garrow JS, Pugh EW (1970) Investigation into the sugar content of endometrial secretion. BJOG 77(10): 891-894.

26. Ménézo Y, Khatchadourian C (1990) Implication of glucose 6 phosphate isomerase (EC 5.3.1.9) activity in blocking segmentation of the mouse ovum at the 2 cell stage in vitro. C R Acad Sci III 310(1): 297-301.

27. Abramczuk J, Solter D, Koprowski H (1977) The beneficial effect of EDTA on development of mouse one-cell embryos in chemically defined medium. Dev Biol 61(2): 378-383.

28. Whitten WK (1956) Culture of tubal mouse ova. Nature 177(4498): p. 96.

29. Collins JL, Baltz J M (1999) Estimates of Mouse Oviductal Fluid Tonicity Based on Osmotic Responses of Embryos. Biol Reprod 60(5): 1188-1193.

30. Dawson KM, Baltz JM (1997) Organic osmolytes and embryos: substrates of the Gly and beta transport systems protect mouse zygotes against the effects of raised osmolarity. Biol Reprod 56(6): 1550-1558.

31. Sakkas D, Urner F, Menezo Y, Leppens G (1993) Effects of glucose and fructose on fertilization, cleavage, and viability of mouse embryos in vitro. Biol Reprod 49(6): 1288-1292.

32. Barbehenn EK, Wales RG, Lowry OH (1974) The explanation for the blockade of glycolysis in early mouse embryos .Proc Nat Acad Sci USA 71(4): 1056-1060.

33. Barbehenn EK, Wales RG (1978) Lowry OH Measurement of metabolites in single preimplantation embryos: a new means to study metabolic control in early embryos .J Embryol exp Morph 43: 29-46.
34. Traxinge RR, Marshall S (1991) Coordinated regulation of glutamine: fructose-6- phosphate amidotransferase activity by insulin, glucose and glutamine: role of hexosamine biosynthesis in enzyme regulation. J Biol Chem 266(16): 10148-10154.

35. Marshall S, Bacote V, Traxinger RR (1991) Complete inhibition of glucoseinduced desensitization of the glucose transport system by inhibitors of mRNA synthesis: evidence for rapid turnover of glutamine:fructose-6phosphate amidotransferase. J Biol Chem 266(16): 10155-10161.

36. Brinster RL (1974) Embryo development. J Anim Sci 38: 1003-1012.

37.Wales RG (1975) Maturation of the mammalian embryo: biochemical aspects. Biol Reprod 12(1): 66-81.

38. Tareq KMA, Obata R, Miah AG, Hamano K, Tsujii H (2005) Ammonia concentration in porcine ovarian developing follicles. J Mamm Ova Res 22(3):185-189.

39. Adibi SA, Lochs H, Abumrad NN, Daniel H, Vazquez JA (1993) Removal of glycyl glutamine by individual tissues: mechanism and impact on amino acid fluxes in postabsorption and starvation. J Nutr 123(2): 325-331.

40. Roth E, Ollenschlager G, Hamilton G, Simmel A, Langer K, et al. (1988) Influence of two lutamine-containing dipeptides on growth of mammalian cells. In Vitro Cell. Dev Biol 24(7): 696-698.

41.Biggers JD, McGinnis LK, Lawitts JA (2004) Enhanced effect of glycyl-Lglutamine on mouse preimplantation embryos in vitro. Reprod Biomed Online 9(1): 59-69. 